\title{
An ethnography of mechanisms employed by the government to hold NGOs in Ethiopia accountable: the case of child focused social protection providers
}

\begin{abstract}
This article provides an ethnographic description of accountability mechanisms employed by governments of developing countries to hold NGOs accountable taking the Ethiopia as a case. It is based on interviews and Focus Group Discussion with key informants with firsthand experience in implementing the mechanisms. The interviews were recorded, transcribed and analyzed using hyper research research software. The resulting description indicates that instead of serving their overt objective, which is to ensure the accountability of NGOs, institutional rituals and institutional and elite interests were forces that sustained the accountability mechanisms. Setting up and refining a central monitoring and evaluation system to ensure upward accountability and, erecting structures for ensuring downward and horizontal accountability were finally proposed to maximize accountability of NGOs in Ethiopia.
\end{abstract}

Keywords: nongovernmental organizations, accountability mechanisms, Ethiopia, developing countries, social protection.
Volume 3 Issue I - 2019

\author{
Daniel Hailu \\ Litmus Research and Consultancy PLC, Ethiopia
}

Correspondence: Daniel Hailu, Litmus Research and Consultancy PLC, Addis Ababa, Ethiopia, Tel +25191272372 I Email danihailu@gmail.com

Received: March 20, 2018 | Published: January 03, 2019

\section{Introduction}

This article provides an ethnographic description of bureaucratic means or mechanisms to hold nongovernmental organizations (NGOs) in Ethiopia accountable before the government. Mechanisms of accountability in this context refer to both processes i.e. a sequence of activities enacted by a mandated public office in holding the NGOs accountable and tools i.e. discrete devises or techniques they apply in that process. ${ }^{1}$ The article aims to call attention to the significant dearth of literature on accountability mechanisms employed by the state in developing countries. Lessons on upward accountability mechanisms are based on international experiences where the financers of NGO projects have been attempting to hold the NGOs accountable. In developing countries, NGOs are almost entirely financed by international donors and receive insignificant or no financial assistance/ grants from their governments. However, although governments of developing countries do not generally finance NGOs, they have increasingly tightened regulation of NGOs. This appears to be due to increasing report of NGO's abuse of resources mobilized from international sources in the name of the people ${ }^{1-5}$ and/or the critical political stands some governments perceived in the operations of the NGOs..$^{6-8}$ Despite these developments, there is a dearth of systematic studies on mechanisms employed by governments to hold NGOs accountable.

In the more developed countries where social service provisioning is contracted to private providers, the state has systems and structures to hold the providers accountable. In this connection, the literature. ${ }^{9-18}$ Has extensively examined the effectiveness of performance-based contractual mechanisms and quality assurance systems that have gained popularity as effective accountability mechanisms. On the other hand, there is virtually no empirical study on accountability mechanisms governments of developing countries have employed as they tighten regulation of a multitude of NGOs they do not finance. Such studies could establish best practices that facilitate or bottlenecks that limit the aggregate effectiveness and impact of mechanisms employed by governments in developing countries to hold NGOs accountable. Focusing attention on the accountability and governance of social protection provisioning by NGOs is particularly important in the context of increasing privatization of social service provision reported globally. ${ }^{12,19,20}$ This is even more critical in the developing countries where a significant percentage of such services are provided by non state actors and beneficiaries do not have the capacity to hold providers accountable. For example, extant systematic studies on social assistance provided by NGOs in Ethiopia reported that in aggregate, NGOs' provided insufficient, unpredictable, erratic and inferior quality social assistance..$^{21,22}$ How have the accountability mechanisms of both donors and the government continued to overlook this suboptimal performance? Have both the government and donors been participating in these mechanisms to simply exhibiting global practices purported to ensure NGOs' accountability, irrespective of their efficacy and efficiency? Have the government and donors simply been exhibiting their political and economic authority respectively over NGOs without regard to actual effectiveness and efficiency of NGOs services?

This ethnographic description provides the basis for answering these questions in relation to accountability mechanisms of NGOs to the state taking Ethiopia as a case. Ethiopia can provide a revelatory case for examining these questions: The government has been accusing of NGOs of abusing resources solicited in the name of the people and serving as instruments for political interference of external forces in domestic political affairs. Consequently, the government has been increasingly tightening regulation of NGOs, which eventuated in the passage by the government of the Proclamation for Registration of Charities and Societies in 2009, which NGOs limits administrative cost of NGOs not to exceed $30 \%$ of their total budget. It also severely restricts NGOs receiving more than $10 \%$ of their budget from external sources from engaging in activities that the law considered political. However, there has been no study of actual mechanisms that the government has been employing to hold NGOs accountable since even before the newly enacted law. Systematic research on mechanisms of accountability by NGOs in Ethiopia is, however, challenging. Difficulty in accessing authentic information regarding practices that 
make up such processes is perhaps the worst challenge. One major reason may be the fear that organizational elites may harbor - a fear that revealing their actual practices could result in diminishment of their legitimacy and the associated economic gain ultimately threatening their organization's very survival. Based on anthropological studies on NGOs in a few African countries, Igoe \& Kelsall (2005) strongly suggested the ethnographic method to addressing this essential research challenge. This study employed the ethnographic research design because, as recommended by Igoe \& Kelsall, it could enable access to the insiders' perspective to generate authentic information on accountability practices of NGOs in Ethiopia.

\section{Method}

This article is based on an ethnographic fieldwork conducted from December 2009 to February 2012 in Ethiopia's capital, Addis Ababa on the broader theme of provision of social protection to Ethiopian children. This description is, however, based on findings of interviews and Focus Group Discussions (FDGs) related to the upward accountability structures of NGOs to the government. Because this is the first systematic study on accountability mechanisms of NGOs in Ethiopia, unstructured interview was employed as a core data collection method to allow exploration of a wide range of relevant issues. All informants were initially asked to describe the overt and covert goals, structures, techniques and processes etc employed by the government to hold NGOs accountable. Subsequent promote question in the course of the interviews helped to explicate various aspects of their emerging descriptions. The interviews were held with three categories of informants. The first category consisted of 25 key informants with each of whom was held an initial exploratory interview on the governance of social services by NGOs in Ethiopia. These informants were individuals who were considered to have rich experience and knowledge on issues related to services to vulnerable children in general and NGO accountability in particular. Their knowledge and experience was gained from their long standing service in or intimate association with one or more of the structures under study. Snowball sampling was applied to identify these informants. It was upon analysis of this set of interviews that the accountability mechanisms were first identified. The remaining two categories of informants represented central institutional players in the identified structures.

The second category of informants consisted of officials in government agencies mandated with roles in monitoring and evaluation of child focused NGOs; namely, the Bureau of Finance and Economic Development (BoED) and the Bureau of Women and children Affairs (BoWCA) of the City Administration of Addis Ababa. At the city level, relevant officers in both BoFED and BoWCA were interviewed. At the sub-city level, officers of BoWCA's sub-city offices of six sub-cities were interviewed and it was considered of little consequence to further interview that of the remaining four offices due to saturation of information. At the woreda (the lowest unit of government administration) level, five FGD were held. Each was held with an average of 4 officers, each representing randomly selected woreda offices of BoWCA in the same sub-city. FGD with woreda officers of conveniently selected five different sub-cities constituted the five FDGs. Again additional FGDs with officers of the woreda offices of the remaining five sub-cities were considered redundant due to data saturation. Participants in the FGDs were delegated by head of the woreda office to represent their respective offices.

The third set of informants consisted of NGO officials. Logistical and methodological requirements for organizational level ethnography required zooming in on one of Addis Ababa's ten subcities masked here as Dusk. Selection of Dusk out of the ten sub-cities was coincidental although Dusk was generally recognized as one of the poorest sub-cities in Addis Ababa, home to a relatively large number of vulnerable children, as well as child-serving interventions. Thirty eight NGOs that run fifty two social service projects reportedly serving a total of 13,090 vulnerable children in Dusk were included in the organizational level ethnography. These consisted of all NGOs recognized by DUSK's office to have provided at least one type of social protection service to vulnerable children. Table 1 below summarizes the above description on methods, sources of data, objectives and length of the interviews and FGDs that constituted the core data for the present analysis.

Table I Methods of data collection, sources of data, number of participants and length

\begin{tabular}{|c|c|c|c|c|}
\hline Objective & Method & Sources of data & $\begin{array}{l}\text { Number of } \\
\text { participants }\end{array}$ & Length \\
\hline \multirow{3}{*}{$\begin{array}{l}\text { To describe from their organization perspectives, } \\
\text { goals, structures and process etc involved in } \\
\text { holding NGOs accountable as well as their personal } \\
\text { perceptions and evaluations and that of others } \\
\text { regarding these institutional features }\end{array}$} & $\begin{array}{l}25 \text { Exploratory } \\
\text { interviews }\end{array}$ & $\begin{array}{l}\text { Key informants selected through snowball } \\
\text { sampling }\end{array}$ & 25 & 1 hour \\
\hline & $\begin{array}{l}6 \text { Unstructured } \\
\text { interviews }\end{array}$ & $\begin{array}{l}\text { One official representing each of the } 6 \text { Sub-city } \\
\text { BoWCAs }\end{array}$ & 6 & $\begin{array}{l}1 \text { hour and } \\
30 \text { minutes }\end{array}$ \\
\hline & $\begin{array}{l}38 \text { semi structured } \\
\text { interviews }\end{array}$ & $\begin{array}{l}38 \text { officers, each representing an NGO in } \\
\text { Dusk that implemented a child focused service } \\
\text { project }\end{array}$ & 38 & 2 hours \\
\hline
\end{tabular}

In addition to the core data obtained through unstructured interviews 25 project proposals and 20 annual reports submitted to the BoWCA were reviewed. Data analysis employed two stages. In the first stage, the content of interviewed data and observational notes was broken down into categories and sub-categories of meaning. To this end, interviews were first recorded and regularly transcribed.
The stored data were iteratively categorized at two levels. At the primarily level, three broad categories of data were distinguished, each labeled 'review', 'monitoring' or 'evaluation'. These categories overlapped with what key informants referred to as elements of a 'project cycle management' (PCM); namely, design, implementation, monitoring and evaluation. At the secondary level, each of the sub- 
categories was further coded based on a particular institutional feature they reflected. A codebook was developed with a relatively long list of codes representing a variety of institutional features which were subsequently classified into four broad groups; namely, 'goals', 'techniques', 'processes' and 'perceptions'. The table below provides

Table 2 Levels, labels and definitions of concepts definitions of labels used to represent concepts at the two levels of categorizations described above. The output from the first stage of data analysis served to construct the portrait of upward accountability mechanisms.

\begin{tabular}{|c|c|c|}
\hline Levels & Labels & Definitions \\
\hline \multirow[t]{3}{*}{ I } & Review & Evaluation of the merits/ demerits of design (proposal) of service project by NGOs \\
\hline & Monitoring & $\begin{array}{l}\text { a routine collection and assessments of performance information aimed at generating early indications of progress in the } \\
\text { achievement of stated project goals }\end{array}$ \\
\hline & Evaluation & systematic assessment of the achievement of outcomes and impact of implemented service project \\
\hline \multirow[t]{4}{*}{ III } & Goals & Overt and hidden goals pursued by institutions and individuals \\
\hline & Structures & $\begin{array}{l}\text { Infrastructure (e.g. offices, vehicles, computers etc), human resources, formal and informal rules (e.g. legislations, tacit } \\
\text { agreements etc) and systems (overt and covert guidelines, manuals) used in facilitation, coordination and integration of } \\
\text { activities. }\end{array}$ \\
\hline & Processes & Day-to-day activities or routines that institutions and individuals serving in them perform as they enact their roles \\
\hline & Perceptions & Individuals' interpretations of the behaviors of institutions and individual actors \\
\hline
\end{tabular}

In the second stage of data analysis, the identified categories and sub-categories of meaning were interpreted against the background of competing perspectives in institutional theory. This aspect of data analysis assumed a hermeneutical approach in which the author is the primary instrument that filters ethnographic data through his perceptual apparatus and subjective opinions as is customary in ethnographic research, which contravenes the underlying assumptions of positivism. ${ }^{23}$ The outputs from the second stage of data analysis informed the discussion, identify issues that may have implications for policy and propose recommendations. The remainder of the article is divided into two sections: First is the description of processes and tools employed by the government to hold the NGOs accountable. This is based on outputs of the first stage of data analysis. This is followed by a succinct interpretation of the ethnographic description from the perspectives of various institutional theories and a discussion of some policy implications of the interpretation.

\section{Accountability mechanisms in action}

The legal basis for mechanism instituted by the Ethiopian government to hold NGOs accountable consists of the federal Proclamation on the Registration of Charities and Societies (PRCS) together the various guidelines that further elaborate on the provision of the PRCS, and the federal and regional proclamation that establish the powers and duties of agencies of the federal and regional governments. The PRCS defines, provides for the establishment of and sets limits to the operation of various categories of charities and societies. The PRCS and the proclamations that establish the powers and duties of agencies of the government provide mandates to agencies involved in holding NGOs accountable. In the context of social assistance to children, the agencies involved were the CSA, the BoFED and the BoWCA. The CSA was mandated with registration and licensing of NGOs, the BoFED was responsible for coordinating planning, implementation, monitoring and evaluation of development plans of various sectors and stakeholders including NGOs and the BoWCA was the sector bureau responsible for ensuring the rights and care and support of children. Based on this legal framework, each mandated government agency has defined internal business processes and structures to fulfill their mandates. They have also signed memorandum of understanding $(\mathrm{MoU})$ to establish division of labor and collaboration on overlapping mandates or interdependent work processes. Accordingly, the abstracted accountability mechanisms in holding child serving NGOs accountable may be divided into three analytically convenient stages; namely, 'proposal appraisal', 'monitoring' and 'evaluation', which are the primary categories identified in the first stage of analyzing the ethnographic data, as reported in the previous section. The rest of this section describes processes under each of these three stages. Since, according to the PRCS, an NGO needs to first be registered and licensed, i.e. acquire legal personhood, before it could be held accountable as a legal entity, processes involved in the acquisition of legal status is deemed beyond the scope of this article.

\section{Proposal appraisal}

A legally registered NGO needs to first sign with the government what is called "operational agreement" before it is able to implement a service project. Next to their license, this agreement is a key document that legitimizes the operations of NGOs. The agreement assigns the NGO the role of project implementation and the government the role of monitoring and evaluation of project implementation. The process towards signing an operational agreement is initiated with BoFED to which a duly registered NGO submits an application for permit to implement a project. BoFED requires NGOs to follow its own temple for preparation of both technical and financial proposals when preparing project proposals they submit for its appraisal. From interview with informants were identified a two stage process involved in appraising applications for operational agreements by NGOs. The first may be called an administrative review that is conducted by BoFED that the applicant NGO is a duly registered with the ACS and the proposed project is within the development plans and priorities of the city with sufficiently justified physical and financial plan. Once satisfied, 
BoFED, in the second stage, refers the proposal to the relevant sector bureau for a second stage technical review. Based on the objectives set by the project, BoFED's officers determine as to which sector bureau to refer a particular proposal to. In the context of services to children, the projects are generally referred to BoWCA. However, informants reported that a project may not fall neatly under the mandates of a sector bureau. An example given by an informant concerned a project that may provide alternative education to $\mathrm{HV}$ positive children with disabilities. Such a project could fall under the mandate jurisdiction of multiple sector bureaus such as of health, education, children affairs. In such case, BoFED forwarded the project document for review by both BoWCA and the HIV/AIDS Prevention and Control Office (HAPCO) of the Bureau of Health. BoWCA and the relevant sector bureaus, if appropriate, reviews the targeting of beneficiaries, the nature of services, the composition of human resources, strategies for services delivery, provision for sustainability proposed by the project among other things. Officials in both BoFED and BoWCA reportedly aimed to ensure that any proposed project did not violate the spirit of the PRCS

In any case, informants in government reported that there was no guide or manual that could structure objective review of projects. Hence, both stages of project proposal review by government were observed to be occasions for negotiation, confrontation, dispute, domination and, in rare cases, learning between officers representing both parties. Frequent concerns raised by BoFED officers relate to involvement in activities that are inappropriate to the category of charity or society for which the NGO was licensed, perceived absence of sufficient provision for sustainability beyond the project period and inflated administrative budget. The following perception summarizes the concerns raised by several officers of BoWCA: Most NGOs project proposals that are sent for our technical review provided insufficient details on the background, strategies and activities of the project. The overwhelming majority of them focus on distribution of often insufficient cash, food and educational materials to targeted children and their families. Rather than making meaningful contribution to the wellbeing of the beneficiaries, these charities have reinforced dependency. Moreover, a significant majority of the projects propose provision of institutional care. We find orphanages serving as mainly transitional home for international adoption, which has become a source of enrichment for those involved in the business.

NGO officers, on their part, expressed their discontent over review of their proposal by both bureaus. The following perception of an informant was shared by many others: Both BoFED and BoWCA are highly bureaucratic. You have to visit each bureau several times before any decision is made on the proposals. To begin with, the officers have multiple duties to give attention to your proposal. Secondly, some of the officers seem to be ill equipped to evaluate a proposal. They pick on minor issues and fail to give meaningful suggestions that can enhance the quality of the proposal. Moreover, the nature of relationship you have with BoWCA and its senior officials could be the major criteria for positive review of your proposal. To establish such a positive relationship you have to provide various supports to the BoWCA such as office furniture and machines or materials its orphanages, regular sponsorship grants that BoWCA administers through its sub city offices. Then you are regarded as 'BoWCA's partner' and are subjected to less scrutiny irrespective of the quality of your proposal or the services you provide. The worst thing is when some officials expect us to give them personal incentive to facilitate speedy approval of our proposal. NGOs officers that have vested interest, lacked confidence in the proposal or frustrate over the review process have given in to the demands of the bureaus and the officers.

In any case, when BoWCA accepts a project proposal often after having the NGO make some or many revisions, then it writes a letter of acceptance to BoFED. Thereafter, BoFED facilitates signing of a tripartite operational agreement. Generally, parties to such an agreement are the incumbent NGO, ${ }^{\mathrm{i}}$ BoFED, BoWCA and other relevant sector bureaus in as appropriate. The agreement is a temple that assigned the role of managing the project to the incumbent NGO while it vests BoFED and BoWCA with the role of monitoring and evaluation of the technical as well as administrative and financial aspects of the project respectively. Upon signing of the operational agreement with an NGO, BoFED writes a letter to BoWCA informing it of approval of the project. With a copy of the same letter, the BoFED and BoWCA also notify their relevant sub-city counterpart of the approval and instruct them to monitor implementation of the project. An NGO can legally begin implementation of the project only upon receipt of the approval letter and signing of the operational agreement.

\section{Monitoring}

As noted earlier, the operational agreement assigns BoFED and BoWCA the responsibility of monitoring technical implementation of the project. It also commits NGOs to submit, in the course of the project period, quarterly implementation reports as well as annual plan of action cascaded from the approved project proposal, annual narrative and audit report to BoFED and BoWCA. In theory, monitoring would consist of reviewing the NGOs' reports and undertaking periodic visits to the project sites to verify the periodic reports and provide feedback to achieve the project's objectives.

Key informants reported that in much practice, only a small percentage of NGOs with operational agreement had submitted report regularly, and the majority had done so intermittently. Informants reported that BoWA did not keep track of NGOs that submitted quarterly report. Oftentimes, when an NGO approached BoWA for various reasons, the file of the NGO is first consulted by the BoWCA officer and inquiries are put to the NGO if the NGO had not been submitting the report. Officers of NGOs had advanced various explanations for this lack or laxity in submitting quarterly report, which BoWCA officers perceived as pretexts. The most common explanations were resignation of a responsible project coordinator that limited its efficiency in paper work or lack of knowledge that this reporting was required (this despite explicit commitment NGOs entered when they signed operational agreement). In any case, NGOs had rarely experienced consequences for lack of meeting this obligation. In any case, the operational agreement does not specify penalty for failing to shoulder responsibilities it assigns to the various parties. Key informants further observed that BoWCA had rarely, if any, reviewed and given feedback on reports submitted to it by the few NGOs or had rarely undertaken monitoring visits. When officers of BoFED or/and BoWCA reportedly visited NGOs, it was either to investigate reported malpractice by NGOs. Such visits were reportedly

\footnotetext{
${ }^{\mathrm{i}}$ When the applicant is an international NGO (INGO) that typically played a financing role, the agreement listed the names and roles of NGOs on whose behalf the INGO may assume responsibility. The INGO would then give a copy of the operational agreement to each of the NGOs to assure them of the legitimacy of the project. This meant that the NGOs under the INGO did not need to sign another operational agreement with the government agencies. An INGO signing operational agreement on behalf of its implementing NGOs, however, represented a minority of cases.
} 
conducted by a mission composed of both BoWCA and BoFED. A key informant had termed these visits 'fact finding missions' than of monitoring activities as per the commitment BoWCA entered in the operational agreement. In such cases, NGOs may attempt to incentivize members of the mission to hide their malpractice. The following case of an NGO that provided institutional case reported by head of a sub city BoWCA was one among several reported cases of NGO malpractice caught read handed by government: There was an NGOs called that provided institutional care to orphans. The NGO was also highly involved in international adoption. We received information from personnel of the orphanage that the children were being feed enjera2 made of decayed teff flour. When we visited the orphanage, the owner refused to let us in saying we had no legal rights to doing so. We returned again with the police with search warrant What we found was five and three quintals of the teff and wheat flour respectively, which had decayed so much that they had geminated worms. We sifted the floor in front of the owner of the organization to show him the worms and later sent samples to laboratory which substantiated our findings. The managing owner was immediately detained and brought to the police station for inquisition. As we were making necessary preparation to sue the orphanage, the laboratory officials refused to give us documentations of their findings. Moreover, the police became reluctant to carry the case forward. The leader of the orphanage released shortly thereafter. He then approached and proposed to me that he would send me to Germany in some pretext if I helped keep hash the case, which I refused. However, it became obvious to us that managing owner was well connected when our appeal to senior authorizes of the government did not result in any action. Perhaps those senior officials also had a share of the pie that is made of out of traffic in children or they may be close acquaintances or relatives with the leaders.

Interview with key informants revealed that absence of a monitoring and evaluation system/ standard in BoFED and BoWCA has made monitoring practices by both bureaus to be highly subjective. This meant that actual supervision, monitoring and follow-up of NGOs project reportedly depended on availability of time, motivation, experience, capacity, creativity, integrity and commitment of officers that undertook them. FDGs have also identified several more specific constraints under this overall constrain. One is limitation in the size and effectiveness of human resources. Available officers were preoccupied with day-to-day arising matters to give attention to planning and implementation of regular project monitoring activities. Secondly, the offices had shortage of transportation facilities that significant constrained their mobility. Thirdly a few, if not none, of the officers were provided with sufficient training on project monitoring and evaluation although their term of references committed them to the assignment. Fourthly, NGOs rarely inform and seek the approval of BoWA when they changed their operational locations, which made them inaccessible for whatever monitoring officers may intend to undertake. Finally, there has been role confusion among the bureau and its sub-city and woreda offices that significantly constrained the involvement of sub-city and woreda offices in monitoring. A key informant summarized the views expressed by several informants in BoWA regarding the role confusion and its roots causes: To begin with, the operational agreement does not specify whether an NGO should also submit reports to the sub-city and woreda offices of BoFED and BoWCA. Hence, some NGOs have submitted their reports only to the bureaus and refused to do the same to sub-city and woreda offices. Officers of such NGO argued that they have signed the agreement with the bureau and are not legally bound to reporting to the sub - city and woreda offices. Outside the operational agreement, however, the Business Process Reengineering (BPR) 3 by government mandates sub-city and woreda offices with the role of monitoring NGOs projects. However, the BPR does not assign distinct roles to the bureau and woreda and sub city offices in the overall monitoring of NGOs. Added to the refusal of some NGOs to report to and be monitored by sub-city and woreda offices, this lack of specificity by the BPR has made the monitoring involvement of the latter very weak. Lack of monitoring systems and standard, competent workforce and infrastructure such as transportation among other (all which are more severe at sub-city and woreda offices than at city level) contributed to negligible involvement of the offices in monitoring. Hence, the extant monitoring of NGOs by government has reportedly been dominated by the BoFED and BoWCA.

\section{Evaluation}

As noted earlier, the operational agreement assigns the BoFED and BoWCA the role of conducting midterm and terminal evaluations. The former is to be conducted half way through a project period and the later at the project's conclusion. Informants explained the objective of midterm evaluation was to assess progress, build on strength and identify bottlenecks that could be removed in the second half of project implementation. The stated objective of terminal evaluation, on the other hand, was to evaluate performance of an NGO and the impacts of its project, ideally to determine if the NGO met its commitment in the operational agreement. However, key informants observed that BoFED and BoWCA were often unable to hold midterm evaluation due to the reported limitations in human resources, logistics and systems. However, BoFED and BoWCA officers may be invited to participate in review meeting that some donors require NGOs to hold as midterm evaluation. BoFED and BoWCA generally undertook terminal evaluations. However, because, as noted earlier, both agencies had not put in place systems for effective evaluation of projects, they could not generally track the dates for termination of each of the project's implementation period to undertake the evaluation. Consequently, key informants observed, NGOs had to always remind and request the agencies to undertake evaluation although the operational agreement did not require NGOs to remind the agencies to undertake the evaluation. An NGO may initiate a backlog of evaluation often when its donor(s) required it for renewal or extension of project agreement or because processing of a new operational agreement with the agencies was conditioned on presentation of reports of the terminal evaluation of a previous project. This, according to informants, means that NGOs initiated the evaluation only when they needed the evaluation report which may not necessarily be right at the end of a project period. Moreover, NGOs might not initiate terminal evaluation processes if they did not needed clearance from BoWCA or/and BoFEED on a previously concluded operational agreement. In any case, upon a reminder or request of an NGO, BoWCA coordinates with BoFED and appointed a team from among its officers to undertake the evaluation. The promptitude with which officers at BoWCA and BoFED responded to the request depended on the priority that the responsible officers may give to the evaluation. If, for reasons stated above, an NGO needed to conduct the evaluation urgently, its officer need to put pressure on the agency's officers through phone calls and visits to their offices. Informants in NGOs also reported incentivizing the officers to expedite the evaluation processes. 
As the case is with monitoring, both BoWCA and BoFED do not have a standard or system for evaluating projects by NGOs. Hence, the quality of evaluation is reportedly depended on availability of time, motivation, experience, capacity, creativity, integrity and commitment of officers that undertook them. Some accounts of the process of evaluation traced the process prior to field visit in which members of the team of evaluators review the files and project documents of the NGOs regarding the history of the organizational as well as the objectives, strategies and activities of the project to be evaluated. The officer visited project site with some or rigorous notes of background information. Holding a meeting with the management board or committee was reported several times as the first activity in the evaluation process. Evaluators in this meeting solicited information on the history of the organization, its structure; the number of employees; the size of beneficiaries and the impact demonstrated; the project sites in the regions, the city and sub-cities; and the challenges posed by and expectation from various stakeholders including governmental organizations, donors, community based organizations and other NGOs. Evaluators took note, in various degree of detail, as explanations were provided by organizational officials and pose additional questions. Evaluators also requested and reviewed some documents such as annual plans and report, project proposal and reports which they took some or little time to review. Next, evaluators conducted visits to check if the information they gathered from the leaders and review of formal reports cohered with the reality on the ground. In doing so, evaluators interviewed key officers of the NGOs including finance officer, purchaser, drivers and personnel administrator to find out about procedures and systems employed in personnel, financial and purchasing management. Evaluators also interviewed beneficiaries and their caregivers regarding weather and if the beneficiaries are obtaining and support and the outcome of the support they have obtain. Additional interviews may also be administered to representatives of local government administrators and community based organizations about the project. Some evaluators reportedly interviewed various stakeholders in the absence of officers and leaders of the NGOs apparently to give them the privacy they needed to express their views freely. However, as reported in the previous section, interviewees were often provided by the NGO and were rarely systematically selected by the evaluating officers. An informant reported, these stakeholder meetings and interviews that donors and government hold to evaluate NGOs projects are often faked! They are staged! NGO officers are notified in advance about visits for monitoring and evaluations. This allows them time to prepare themselves and participating beneficiaries. Stakeholders to be interviewed are careful selected and prepared by NGOs and rarely do evaluators themselves randomly select the stakeholders they interview. Consequently, interviewees are rarely critical of NGOs and, in fact, tend to commend the support that the NGO provides to ensure the favor of NGO leaders and continuity of the project.

Once primary information gathering was thus completed, evaluators reconvened with leaders of the NGO to share findings and obtain their comments. This involved commending the organization for its strength but largely dwelling on identified weakness. Officials of the organizations, on their part, either attempted to defend or promise to correct the stated weakness. Finally, the evaluators completed the terminal evaluation form prepared by BoWCA which solicited detailed evaluation report. The form also required evaluators to make recommendations as to whether or not the project should be extended. In the course of the evaluation, NGOs reportedly provided various 'services' or 'incentives' to evaluators. Many NGOs devoted vehicle to evaluators for the entire period of the evaluation including transportation to and from the evaluators home, lavish refreshments and meals and/ or offering of per diem reportedly between birr 100 and 500 per day ${ }^{4}$. Informants differed on their perception of the motives underlying NGOs offer of these 'services' but the following view appears to be a more balanced perception: We can agree that these consist of the 'services' or 'incentives provided by NGOs to evaluators. But, in my view NGOs differ in the motives that underlie their provision of these 'services'. Some NGOs may provide them to win favorable evaluation, which determined subsequent decision on project extension. Others may do so to facilitate the evaluation or/and as an expression of showing hospitality to guests traditionally expected of hosts than to win a favorable evaluation. I personally know a few organizations that take great care such that their gesture of hospitality may not be misconstrued. These have been offered only tea, soft drinks and kollo and, in some cases, lunch and avoiding giving of per diem. In any case, it is in rare cases when an NGO committed blatant misconduct of a very serious type, which can obviously implicate the evaluators that extension is not recommended and the license of the NGO could even be revoked.

\section{Discussion}

The foregoing was a description of the bureaucratic means employed by the Ethiopian government to hold NGOs providing social protection services to children accountable. This description of accountability mechanisms as forms of bureaucracy may be interpreted from a variety of theoretical perspectives on bureaucracy. A classic perspective may be derived from the Weberian proposition that bureaucratic means are to ensure effectiveness and efficiency (Weber, 1968). In the context of the accountability mechanisms under discussion, this proposition implies that the mechanisms that the government has put in place have been effective in ensuring the accountability NGOs. Based on the foregoing description, it is not possible to conclusively attribute any accountability that the NGOs may have exhibited to the described mechanisms. The description, on other hand, provided several proxy indicators that appear to have significantly limited the effectiveness of the mechanisms. This includes absence of standards, limited competent workforce and infrastructure. The description appears to provide support for the propositions of institutional theory and rational choice institutionalism regarding drivers of bureaucracies, irrespective of their efficiency and effectiveness. Institutional theory. ${ }^{24-28}$ Proposes that bureaucratic means are simply organizational norms, symbols and culture that participants unwittingly but routinely participate without concern about their effectiveness and efficiency. In the context of the accountability mechanisms, actors in government and NGOs appear to be unwittingly but routinely participating in the production and reproduction organizational forms such as appraisal of proposals, periodic reports, monitoring visits, midterm and terminal evaluations to simply exhibit globally accepted practices for ensuring accountability, irrespective of their efficacy and efficiency. Jepperson ${ }^{29}$ would regard these accountability mechanisms as chronically reproduced and selfactivating social patterns. In this connection, Jepperson distinguished between institutions and social action. Whereas social action requires recurrent collective mobilization in order to secure the reproduction of a pattern, institutions such as the accountability mechanism under discussion are supported and sustained by organizational routines and taken for granted procedures, irrespective of their effectiveness or efficiency. 
The description also appears to provide support for a perspective of rational choice institutionalism. ${ }^{30-33}$ which proposes interest to be the main deriver of institutional processes. According to rational choice institutionalism, the driver of bureaucracies is the social, political and economic benefits and advantages actors aspire to accrue out of structured interaction with other actors. In the context of the accountability mechanism under discussion, the political and economic interests of the government and NGOs as institutions and that of the individuals operating in these institutions may be regarded as drivers of the accountability mechanisms. The government had long been accusing NGOs elites of abusing resources donated in the name of vulnerable populations and engaging in subversive activities that promoted external political interests, which has eventually led to the passage of the highly controversial PRCS. Informants observed that the mechanisms under discussion only served to pick on and punish only those NGOs which the government perceives to be against its political and economic interests rather than to effectively hold the entire NGOs establishment to account. NGOs, on the other hand, appeared to have sustained themselves by employing such strategies identified by Oliver $^{34}$ as acquiescence, compromise, avoidance, defiance and manipulation. Informants also perceived the mechanisms as having provided a context for government evaluators and leaders of NGOs for promoting their economic interest. More specifically, in the context of implementing the mechanisms, some NGO elites are perceived to have provided the evaluators incentives so the later may overlook the former's malpractices. Thus, the aggregate accountability mechanism appeared to have become arenas where the government and the NGOs and their elites negotiated and compromised their interests. Given the above interpretations, the description demonstrates that despite many time-consuming and bureaucratic procedures intended to ensure the accountability of NGOs in Ethiopia, there is no guarantee that this objective is served. The description, on other hand, reveals that institutional rituals and institutional and elite interests rather than commitment to ensuring accountability of NGOs are forces that sustain the accountability mechanisms.

\section{Implications for policy}

To reform the above described bureaucratic means to ensure accountability in the best interest of vulnerable populations requires transformation of the established institutional culture and putting in place checks and balances to minimize gaps that could be used for the promotion of vested interests. Setting up performancebased contractual mechanisms and quality assurance system have reportedly helped governments with a well developed welfare systems to effectively hold service providers accountable since it could provide incentive and impose penalties commensurate with their performance according to contracts. ${ }^{10,12}$ Achieving this in the context of developing countries requires commitment and extensive dialogue and negotiation within and among the government, donors and NGOs. Donors and government need to be willing to partner in building a central monitoring and evaluation system that caters for the needs of a diversity of service projects. Even the diversity of donors need to be willing to harmonize their own monitoring and evaluation frameworks and practices. If a central monitoring and evaluation system is achieved, however, it accrues multiple advantages to all stakeholders. To begin with, it services has a platform where the various stakeholders could jointly learn about and work towards improving not only the effectiveness but also efficiency of the models of service delivery. It also significantly the aggregate reduce an administrative cost that is required by unilateral monitoring and evaluation of specific projects they finance. It also reduces the transactional cost that NGOs incur in order to meet the accountability demands of their multiple stakeholders. Once set up, progressive improvement in the performance of the system may also be informed by an ongoing action research on the extent to which the system promotes "quality service delivery and responsible program administration as well as the fiscal mechanisms that promote accountability while facilitating collaboration" as suggested by Collins-Camargo et al, ${ }^{12}$ and avoids 'co-optation and abuse of power by donors and regulators', and 'loss of innovation and diversity as a result of more oversight and regulation' as cautioned by Biswas. ${ }^{35}$

International experience suggests that upward accountability mechanism, however effective, still needs to be complemented with downward and horizontal accountability mechanisms if the accountability of NGOs is to be enhanced. ${ }^{36-42}$ Downward accountability refers to measures that NGO's take to involve beneficiaries in determination of objectives, allocation and utilization of budgets, monitoring of project implementation and evaluation of outputs and outcomes among other things. Downward accountability is particularly critical since beneficiaries are the primary claim holders on NGO services but tend to be vulnerable groups that lack the power and capacity to claim their rights. Informants reported that many donors of Ethiopian NGOs attempt to enforce downward accountability by requiring NGOs to involve beneficiaries and local stakeholders in identification of needs, targeting and review meetings. Independent study does not exist to systematically verify the claims of NGOs that they involve beneficiaries in design and management of projects. However, another article by the author (under review) found that NGOs often successfully circumvent donors' requirement that NGOs involve beneficiaries in monitoring and evaluation of the projects. The study also found the deeply entrenched norms of hieratical social structure ${ }^{43}$ disabling beneficiaries from being critical of NGO practices. These suggest to the need to vigorously enforce downward accountability measures. First, any mechanism for downward accountability may need to first be given a legal basis. Unfortunately, the PRCS does not obligate NGOs to "inform their beneficiaries about their budget" or "involve their beneficiaries in planning and monitoring of expenditures". ${ }^{44}$ Once a legal basis is present, stakeholders may explore the utility of various downward accountability mechanism such as information disclosure, participation mechanism, and complaints procedures identified by Noor ${ }^{37}$ Concomitant building of the capacity of beneficiaries to claim their rights is critical.

Moreover, mechanisms of upward and downward accountability need to also be complemented by horizontal accountability. Horizontal accountability refers to the expectations and inter-organizational behaviors of collaborators within a network of organizations providing similar services which can lead to development of reciprocal relationships and a sense of accountability to members of the network. ${ }^{36}$ Informants lamented about an almost complete absence of horizontal accountability practices in Ethiopia. They observed networks of NGOs focusing more on positioning for resource mobilization from international donors than setting and enforcing standards that can ensure effective and efficient services. Initial attempts where NGOs came together to draft an NGO code of conduct had not been pursued. 
Informants argued that this was because NGOs in Ethiopia lacked cohesion that such an undertaking required, confirming Clark's $\mathrm{s}^{45}$ earlier observation that relationship among NGOs in Ethiopia had been characterized by internal divisions and jealousy. Hailu \& Northcut ${ }^{46}$ traced this to suspicion and competitiveness that underlies lateral relations in the dominant culture, which are explicated in Korten's ${ }^{43}$ monumental work on psychological problems of modernization in Ethiopia. In order to develop a culture of cooperation and trust and put in place a system for self regulation, NGOs could identify and benchmark a range of international experience on NGO self regulation such as those documented by Naidoo ${ }^{47} \&$ Mark. $^{48}$

\section{Conclusion}

This article provided a description of accountability mechanisms employed by governments of developing countries taking the Ethiopia as a case. The description seems to suggest that instead of serving their overt objective, which is to ensure the accountability of NGOs, institutional rituals and institutional and elite interests were forces that sustained the accountability mechanisms. Setting up and refining a central monitoring and evaluation system to ensure upward accountability and, erecting structures for ensuring downward and horizontal accountability were finally proposed to maximize accountability of NGOs in Ethiopia. ${ }^{49,50}$

\section{Acknowledgments}

None.

\section{Conflicts of interest}

The author declares that there is no conflicts of interest.

\section{References}

1. Ebrahim A. Making sense of accountability: conceptual perspectives for northern and southern Nonprofits. Nonprofit Management \& leadership. 2003b;14(2):191-212.

2. Gibelman M, Gelman SR. Very public scandals: nongovernmental organizations in trouble. Nonprofit and Voluntary Sector Quarterly. 2001;12(1):49-66

3. Gibelman M, Gelman SR. A Loss of Credibility: Patterns of Wrongdoing Among Nongovernmental Organizations. Voluntas: International Journal of Voluntary and Nonprofit Organizations. 2004;15(4):355-381.

4. Young DR, Bania N, Bailey D. Structure and accountability: a study of national nonprofit associations. Nonprofit Management and Leadership. 1996;6(4):347-365.

5. Hancock G. Lords of Poverty: The free-wheeling lifestyles, power, prestige and corruption of the multi-billion dollar aid business. London: Mandrain. 1991.

6. Edwards M, Hulme D. Too Close for Comfort? The Impact of Official Aid on Nongovernmental Organizations. World Development. 1996;24(6):961-973.

7. Bartton M. The politics of government-NGO relations in Africa. World Development. 1989;17(4):569-587.

8. Mohan G. The disappointments of civil society: the politics of NGO intervention in northern Ghana. Political Geopgrahy. 2002;21(1):125154

9. Heinrich CJ. Evidence-based policy and performance management: Challenges and prospects in two parallel movements. American Review of Public Administration. 2007;37(3):255-277.
10. Garstka Teri, Collins-Camargo C, Hall J, et al. Implementing Performance-Based Contracts and Quality Assurance Systems in Child Welfare Services: Results From a National Cross-Site Evaluation. Journal of Public Child Welfare. 2012;6(1):12-41.

11. Meezan W, McBeath B. Moving Toward Performance-Based, Managed Care Contracting in Child Welfare: Perspectives on Staffing, Financial Management, and Information Technology, Administration in Social Work. 2011;35(2):180-206.

12. Collins-Camargo $\mathrm{C}$, McBeath B, Ensign E. Privatization and Performance-Based Contracting in Child Welfare: Recent Trends and Implications for Social Service Administrators. Administration in Social Work. 2011;35(5):494-516.

13. Martin LL. Performance-based contracting (PBC) for human services: A review of the literature. Orlando, FL: Center for Community Partnerships. 2003.

14. Martin LL. Performance-based contracting for human services: Does it work? Administration in Social Work. 2005;29(1):63-77.

15. McBeath B, Meezan W. Governance in motion: Service provision and child welfare outcomes in a performance-based, managed care contracting environment. Journal of Public Administration Research and Theory. 2010;20(1):i101-i123.

16. Meezan W, McBeath B. Nonprofits moving to performance-based, managed care contracting in foster care: Highlights of research findings. MI: Michigan Nonprofit Research Program. 2004.

17. Kearney KA, McEwen E. Striving for excellence: Extending child welfare performance based contracting to residential, independent and transitional living programs in Illinois. Professional Development: International Journal of Continuing Social Work Education. 2007;10(3):32-48.

18. Kearney KA, Bloom-Ellis B, Thompson R. Breaking down the silos: Lessons learned from the expansion of performance-based contracting to residential treatment services in Illinois. Journal of Public Child Welfare. 2012;6(1):83-107.

19. Croll E. Social Welfare Reform: Trends and Tensions. The China Quarterly. 1999;159:685-699.

20. Plantinga M, Corral A. Regulating private welfare: The causes and consequences of failures in the provision of private welfare. Presented at Biennial Conference of the Standing Group on Regulatory Governance of the ECPR 'Regulation in the Wake of Neoliberalism. 2008;5-7.

21. Hailu D. An Ethnography of Social Assistance to Ethiopian Children by Non-governmental Organizations: Types, Adequacy and Predictability. Social policy \& administration. 2015;51(5):817-836.

22. Little P. Food Aid Dependency in Northeastern Ethiopia: Myth or Reality?. World Development. 2008;36(5):860-874.

23. LeCompte MD, Goetz JP. Ethnographic data collection and analysis in evaluation research. Educational Evaluation and Policy Analysis, Fall. 1982;4(3):387-400.

24. Silverman D. The Theory of Organizations: A Sociological Framework. New York: Basic Books. 1971.

25. Meyer J, Rowan B. Institutionalized Organizations: Formal Structure as Myth and Ceremony. The American Journal of Sociology. 1997;83(2):340-363.

26. DiMaggio P, Powell WW. The iron cage revisited: Institutional isomorphism and collective rationality in organizational fields. American Sociological Review. 1983;48(2):147-160.

27. DiMaggio P. Introduction. In: Dimaggio \& Powell WW, Editors. The new institutionalism in organizational analysis. Chicago: University of Chicago. 1991;5-20. 
28. Scott WR. Institutions and Organizations: Ideas and Interests. Thousand Oaks, CA: Sage. 2008.

29. Jepperson. Institutions, institutional effects, and institutionalization. In: Dimaggio \& Powell WW, Editors. The new institutionalism in organizational analysis. Chicago: University of Chicago. 1991;204-231.

30. March JG, Oslen JP. Rediscovering Institutions: The Organizational Basis of Politics. New York: The Free Press. 1989;843-844.

31. Hepsle KA. Rational Choice Institutionalism. In: Binder S, et al. Editors. Oxford Handbook of Political Institutions. Oxford University Press. 2006.

32. Lownpes V. Varieties of new institutionalism: A critical appraisal. Public Administration. 1996;74(2):181-197.

33. Peter BG. Institutional theory in political science: the 'new institutionalism. New York: Continuum. 2005.

34. Oliver C. Strategic response to institutional processes. Academy of Management Review. 1991;16(1):145-179.

35. Biswas S. NGO Accountability: Issues and Possibilities. KIIT Journal of Management. 2009;6(1\&2);1-25.

36. Romzek B. A preliminary Theory of Informational Accountalbity among Network Organiztaional actors. Public Administration review. 2012;72(3):442-453.

37. Nurul Hidayana Mohd Noor. Enforcing Downward Accountability for Nonprofit Effectiveness: A Case Study of Malaysian NGO. International Journal of Innovation, Management and Technology. 2015;6(2):93-99.

38. Agyemang G, Awumbila M, Unerman O’Dwyer B. NGO Accountability and Aid Delivery. Research report 110. The Association of Chartered Certified Educational Trust, London. 2009;1-40.

39. Lloyd R, Casas L. NGO Self-Regulation: Enforcing And Balancing Accountability. One World Trust, London. 2006;1-8.
40. Lee J. NGO Accountability: Rights and Responsibilities Centre for Applied Studies in International Negotiations (CASIN). Geneva. 2004.

41. Lloyd R. The Role of NGO Self-Regulation in Increasing Stakeholder Accountability. One World Trust, London. 2005.

42. Jordan L. Mechanisms for NGO Accountability. GPPI Research paper series No. 3. Global Public Policy Institute, Berlin. 2003;1-20.

43. Korten D. Planned Change in a Traditional Society, Psychological Problems of Modernization in Ethiopia. New York: Praeger. 1972.387.

44. Hailu D. Towards an Integrated Social Protection Strategy in Ethiopia's Forthcoming PRSP - the Growth and Transformation Plan, 2010/112015/16, Working Paper no. 11. Addis Ababa: The Ministry of Finance and Economic Development and UNICEF. 2010.

45. Clark J. Civil Society, NGOs, and Development in Ethiopia: A Snapshot View. Washington, DC: The World Bank. 2000:1-32.

46. Hailu D, Northcut T. Ethiopia's Social Protection Landscape: Its Surface and Underlying Structures. International Social Work. 2012;56(6)

47. Naidoo K. The end of blind faith? Civil society and the challenge of accountability, legitimacy and transparency. Accountability Forum. 2004;2:14-23.

48. Sidel M. Trends in nonprofit self-regulation in the Asia Pacific region: initial data on initiatives, experiences and models in seventeen countries. APPC. 2003

49. James G, Johan P Olsen. The New Institutionalism: Organizational Factors in Political Life. American Political Science Review 78. 1984;78(3):734-49.

50. Schensul LS, Schensul J, Le Compte M. Essential ethnographic methods: Observations, interviews and questionnaires. Walnut Creek, California: AltaMira Press. 1999 